\section{Dendritic Copper Catalysts for Homogeneous Click Chemistry in Water}

Polymer-Supported

Synthesis

\section{Key words}

dendrimers

Huisgen cycloaddition

click chemistry

copper catalysis

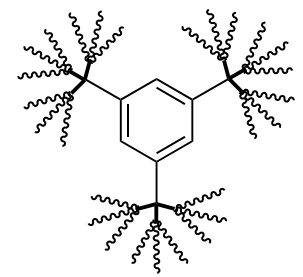

$\underset{\mathrm{H}_{2} \mathrm{O}, 25^{\circ} \mathrm{C}}{\stackrel{\mathrm{CuSO}_{4} \cdot 5 \mathrm{H}_{2} \mathrm{O}}{\longrightarrow}}$

dendrimer 1

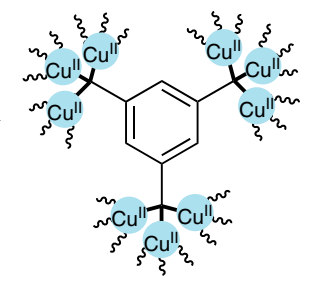

pre-catalyst 1-Cull

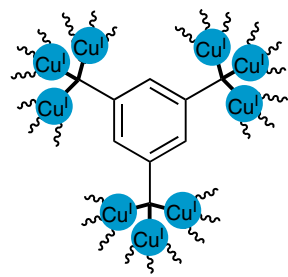

catalyst $1-\mathrm{Cu}^{\prime}$

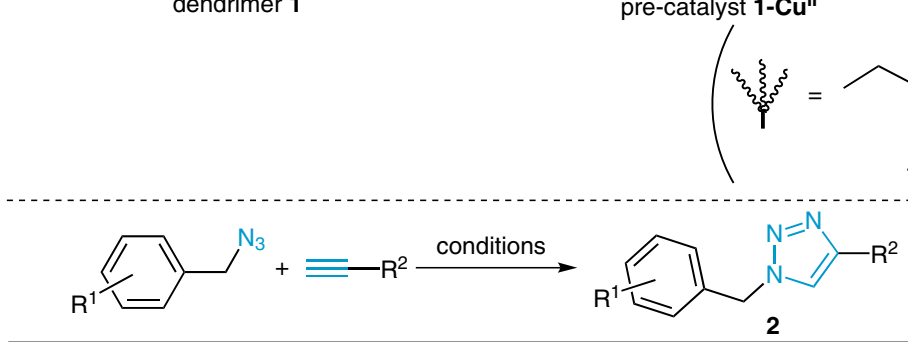

conditions A: dendrimer 1 (1 mol\%), [hexabenzyltren-CulBr 3 (0.1 mol\%), $\mathrm{H}_{2} \mathrm{O}, 25^{\circ} \mathrm{C}, 3 \mathrm{~h}$ conditions B: catalyst 1- $\mathrm{Cu}^{\prime}(4-50 \mathrm{ppm} \mathrm{Cu}), \mathrm{H}_{2} \mathrm{O}, 30^{\circ} \mathrm{C}, 24 \mathrm{~h}$ conditions C: catalyst 1-Cu' (4-50 ppm Cu'), $\mathrm{H}_{2} \mathrm{O}, 35^{\circ} \mathrm{C}, 24 \mathrm{~h}$

Selected examples:

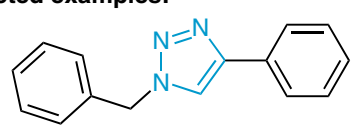

2a $\mathrm{R}^{1}=\mathrm{H}, \mathrm{R}^{2}=\mathrm{Ph}$

conditions A: $91 \%$ yield

conditions B: $99 \%$ yield (4 ppm Cul)

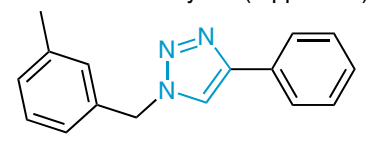

2c $\mathrm{R}^{1}=\mathrm{Me}, \mathrm{R}^{2}=\mathrm{Ph}$

conditions A: $90 \%$ yield

conditions B: $89 \%$ yield (20 ppm Cu')<smiles>CS(C)(C)(=O)c1cn(Cc2ccccc2)nn1</smiles>

2b $\mathrm{R}^{1}=\mathrm{H}, \mathrm{R}^{2}=\mathrm{TMS}$

conditions A: $89 \%$ yield

conditions C: $81 \%$ yield (20 ppm Cu')

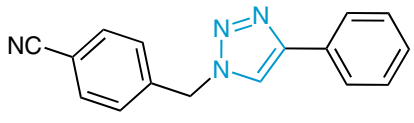

2d $\mathrm{R}^{1}=\mathrm{CN}, \mathrm{R}^{2}=\mathrm{Ph}$

conditions $A: 90 \%$ yield

conditions B: $90 \%$ yield (50 ppm Cu')

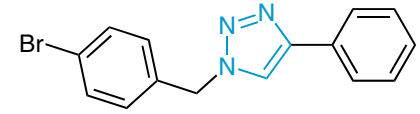

2e $\mathrm{R}^{1}=\mathrm{Br}, \mathrm{R}^{2}=\mathrm{Ph}$

conditions A: $96 \%$ yield

conditions C: $89 \%$ yield (50 ppm Cu')
Significance: The dendrimer 1 consists of water/ organic compatible 27 triethyleneglycol (TEG) termini and a hydrophobic core (for the preparation of 1, see: Chem. Commun. 2013, 49, 8169). [Hexabenzyltren-Cu]Br $\mathbf{3}$ and $\mathbf{1}$ promote the click reaction of benzyl azides and phenyl acetylenes in water to give the corresponding triazoles in 89-96\% yield. The catalyst 1-Cu' (4-200 ppm Cu'), prepared from $\mathrm{CuSO}_{4} \cdot 5 \mathrm{H}_{2} \mathrm{O}$ and $\mathrm{NaAsc}$, also catalyzed the click reaction in $81-99 \%$ yield.
Comment: The TEG termini render the dendrimer 1 water-soluble, and the hydrophobic core allows solubilization of the hydrophobic compound $\mathbf{3}$ and the substrates in water. The interaction between $\mathbf{1}$ and $\mathbf{3}$ was shown by selective ${ }^{1} \mathrm{H}$ NMR shifts and a NOESY spectrum. The micelle nanoreactor 1 was recycled ten times ( $10^{\text {th }}$ reuse: $\mathbf{2 a}, 91 \%$ yield). The click reaction was performed with $1 \mathrm{ppm}$ $\mathbf{1 - C \mathbf { C } ^ { \prime }}$ to give $\mathbf{2 a}$ in $50 \%$ yield, whose turnover number (TON) and turnover frequency (TOF) were 510000 and $21200 \mathrm{~h}^{-1}$, respectively.

sYNFACTS Contributors: Yasuhiro Uozumi, Yoichi M. A. Yamada, Rikako Ishii

Synfacts 2014, 10(12), $1331 \quad$ Published online: 18.11.2014

Dol: 10.1055/s-0034-1379574; Reg-No.: Y13214SF 